\title{
Clinical and radiological outcomes of multilevel cervical laminoplasty versus three-level anterior cervical discectomy and fusion in patients with cervical spondylotic myelopathy
}

\author{
Jong Joo Lee ${ }^{1 \#}$, Nam Lee ${ }^{2 \#}$, Sung Han $\mathrm{Oh}^{1}$, Dong Ah Shin ${ }^{3}$, Seong $\mathrm{Yi}^{3}$, Keung Nyun Kim ${ }^{3}$, \\ Do Heum Yoon ${ }^{3}$, Hyun Chul Shin ${ }^{4}$, Yoon $\mathrm{Ha}^{3}$ \\ ${ }^{1}$ Department of Neurosurgery, Bundang Jesaeng Hospital, Seongnam, Korea; ${ }^{2}$ Department of Neurosurgery, Yonsei Cheok Hospital, Busan, Korea; \\ ${ }^{3}$ Department of Neurosurgery, Spine, and Spinal Cord Institute, Yonsei University College of Medicine, Seoul, Korea; ${ }^{4}$ Department of Neurosurgery, \\ Kangbuk Samsung Hospital, Sungkyunkwan University School of Medicine, Seoul, Korea
}

"These authors contributed equally to this work.

Correspondence to: Yoon Ha, MD, PhD. Professor, Department of Neurosurgery, Spine and Spinal Cord Institute, Yonsei University College of Medicine, Severance Hospital, 50 Yonsei-ro, Seodaemun-gu, Seoul 120-752, Korea. Email: hayoon@yuhs.ac.

Background: Cervical spondylotic myelopathy (CSM) is one of the most common causes of spinal cord impairment in elderly patients. However, a consensus has yet to be reached on the ideal method of surgical intervention. In this study, we investigated serial changes of radiological findings after three-level anterior cervical discectomy and fusion (ACDF) and multilevel laminoplasty and attempted to identify the radiological parameters affecting long-term clinical outcomes in CSM.

Methods: Of the 152 patients with multilevel CSM treated with three-level ACDF and multilevel laminoplasty, 42 had complete radiological parameters both before and 2 years after surgery (three-level ACDF, 22 patients; multilevel laminoplasty, 20 patients). Radiological parameters included spinal cord signal intensity (SI) changes on magnetic resonance imaging (MRI). Clinical outcomes including the Japanese Orthopaedic Association (JOA) score, neck disability index (NDI), Oswestry disability index (ODI), and 36Item Short Form Health Survey score were measured.

Results: The ACDF group showed significant restoration of segmental lordosis postoperatively (preoperatively: $2.21^{\circ}, 6$ months: $8.37^{\circ}, \mathrm{P}=0.026$ ), and segmental and cervical range of motion (ROM) was markedly reduced and well maintained until the final follow-up (preoperatively: $25.48^{\circ}, 24$ months: $4.35^{\circ}, \mathrm{P}<0.001$; preoperatively: $41.71^{\circ}, 24$ months: $20.18^{\circ}, \mathrm{P}<0.001$ ). The recovery rates of the JOA score were $42.85 \%$ and $57.40 \%$ in the ACDF and laminoplasty groups, respectively, although this difference was not statistically significant. Multivariate regression analysis demonstrated that signal change on MRI significantly affected the recovery rate $(\mathrm{P}=0.003)$. The visual analog scale (VAS) score and NDI decreased considerably only in the laminoplasty group, and device complications were confirmed only in the ACDF group (incidence rate $=36.5 \%$ ).

Conclusions: Multilevel laminoplasty showed better radiological and similar clinical outcomes. ACDF had more surgical complications. Spinal cord SI change on preoperative MRI was the independent risk factor for poor clinical outcomes. We recommend laminoplasty instead of three-level ACDF to treat multilevel CSM.

Keywords: Anterior cervical discectomy and fusion (ACDF); laminoplasty; cervical spondylotic myelopathy (CSM); lordosis; signal intensity (SI)

Submitted Feb 07, 2020. Accepted for publication Jul 22, 2020.

doi: 10.21037/qims-20-220

View this article at: http://dx.doi.org/10.21037/qims-20-220

\footnotetext{
$\wedge$ ORCID: 0000-0003-0905-0330.
} 


\section{Introduction}

Cervical spondylotic myelopathy (CSM) is a common cause of spinal cord impairment in elderly patients around the world $(1,2)$. It can manifest with various symptoms and signs, including motor and sensory abnormalities due to dysfunction of the cervical spinal cord (3). The pathophysiology of CSM is believed to be bi-factorial, with static and dynamic factors (4). The static factor is caused by canal stenosis, and the dynamic factor causes repetitive injury to the spinal cord $(5,6)$. Ito et al. reported that the autopsy results of patients with CSM exhibited grey matter atrophy and white matter demyelination (7).

The symptoms of CSM are commonly relieved with surgical decompression. Surgical approaches are divided into anterior and posterior approaches, or sometimes a combined anterior and posterior approach. Both anterior decompression $(8,9)$ and laminoplasty $(10-12)$ are considered safe and effective treatment options. Fehlings et al. claimed that the anterior and posterior techniques have equivalent efficacy in the treatment of CSM (13). Yet, it remains controversial which surgical method is most suitable (14-17). However, these studies only demonstrated clinical outcomes, not serial radiological changes, and did not identify the factors associated with the differences in clinical outcomes in both groups.

For multilevel CSM, anterior cervical discectomy and fusion (ACDF) is a representative surgical method of the anterior approach, while multilevel cervical laminoplasty, along with laminectomy with instrumented fusion, are characteristic surgical techniques of the posterior approach (18). This study aimed to investigate the serial changes of radiological findings and clinical outcomes in patients who underwent three-level ACDF or multilevel laminoplasty to treat symptomatic multilevel CSM. Also, we aimed to identify the radiologic parameters affecting clinical outcomes, and to establish which surgical method is most appropriate for treating multilevel CSM.

\section{Methods}

From January 2011 to May 2013, 152 patients who had been diagnosed with multilevel CSM at our institution and treated with either three-level ACDF or multilevel laminoplasty were enrolled. These included 69 patients who had undergone three-level ACDF and 83 patients treated with multilevel laminoplasty. From this initial cohort, 42 patients who had complete radiologic parameters preoperatively and at 2 years postoperatively were retrospectively investigated (three-level ACDF, 22 patients; multilevel laminoplasty, 20 patients).

This study was approved by the Yonsei University institutional review board (IRB No.: 4-2012-0687). Informed consent was waived due to the retrospective analysis design. Surgical treatment was provided to patients displaying neurologic symptoms (such as axial neck pain, arm pain, motor/sensory deficits, or gait disturbance) and/or urinary symptoms and corresponding neural element compression on magnetic resonance imaging (MRI). Patients with any of the following were excluded: ossification of the posterior longitudinal ligament; ossification of the ligamentum flavum; a previous history of cervical spine surgery; or other neurologic disorders, trauma, or tumor.

The patients were divided into two groups: a threelevel ACDF group (ACDF group, $n=22$ ) and a multilevel laminoplasty group (laminoplasty group, $n=20$ ). We subsequently compared various radiological parameters, clinical outcomes, surgical outcomes, and complications between the groups.

\section{Surgical procedures}

The method of surgery was chosen according to whether the patient had segmental lordosis (SegL). In cases of straight alignment or kyphosis, the anterior approach was performed. However, when segmental alignment was relatively maintained, the posterior approach was attempted.

\section{ACDF group}

ACDF was performed under general anesthesia with the conventional standard right-sided Robinson-Smith anterior approach. The base of the uncinate process was indicated as a landmark for the width of the vertebral body. Following each total discectomy, the posterior longitudinal ligament was also divided and removed with bony spur confirming adequate dural decompression. Furthermore, the empty disc space was replaced with an allograft bone block to achieve arthrodesis in most patients (19). To attain firm fixation, screws were inserted into the anterior plate of each vertebral body.

\section{Laminoplasty group}

A posterior midline approach was used under general 
anesthesia. The patient was placed in the prone position and the head was fixed with a Mayfield head holder without traction. The operating table was controlled under reverse Trendelenburg position. Subsequently, both of the patient's shoulders were taped down and the neck was slightly flexed. After muscular dissection, the lamina and spinous processes were exposed. Expansive open-door laminoplasty was performed in all patients using a plate fixation system and treating lesions involving more than three disc space levels was preferred. The opening side was usually the side with severe radicular symptoms or more aggressive stenosis.

\section{Radiological assessment}

To evaluate the serial change of radiological findings and to identify the most valuable parameter, various radiological parameters were measured. These included: whole cervical lordosis (CL, from C2 to C7), SegL (confined to the instrumented level), whole cervical flexion angle (from C2 to C7), segmental flexion angle (confined to the instrumented level), whole cervical extension angle (from $\mathrm{C} 2$ to $\mathrm{C} 7$ ), segmental extension angle (confined to the instrumented level), whole cervical range of motion (ROM) (from C3 to C7), segmental range of motion (SegROM, confined to the instrumented level), and $\mathrm{C} 2-7$ sagittal vertical axis (SVA) by plain radiographs (including flexion and extension views). Images were obtained preoperatively and at 6,12 , and 24 months postoperatively.

Preoperative T2-weighted MRI scans were also evaluated to investigate the effect of spinal cord signal intensity (SI) change. We divided spinal cord SI into three degrees of change: no change, intermediate change, and definite change. Moreover, the $\mathrm{K}$-line was measured to investigate the effect of cervical alignment using T2-weighted MRI scans $(20,21)$. Finally, we confirmed the fusion rate and graft subsidence rate in the ACDF group using computed tomography (CT) scans at 12 and 24 months postoperatively. Cage subsidence was defined as endplate breakage and reduction of the disc space height due to implant migration into the adjacent vertebral body (22).

\section{Neurological assessment}

Considering that CSM patients typically complained of symptoms of myelopathy and radiculopathy, we investigated various neurological and functional measurement scales. Neurological outcomes were assessed using the visual analog scale (VAS), neck disability index (NDI), and the 36-Item Short Form Health Survey, including the physical component score (PCS) and mental component score (MCS). The arm-trunk-leg-bladder scores of the Japanese Orthopaedic Association (JOA) were also assessed to evaluate the recovery rate (RR), which was calculated according to the report by Hirabayashi et al. (23). Furthermore, we performed Pearson's correlation analyses with different factors to identify the primary factor affecting the RR.

\section{Statistical analysis}

The independent t-test was used to compare parameters between the patient groups. The chi-square test was used to compare parameters before and after surgery in each group. The analysis of variance test was used to compare the effect of spinal cord SI change. Correlation analysis and the multivariate regression test were used to identify the key factor affecting the RR. All statistical analyses were performed using the Predictive Analytics Software (PASW) Statistics 18 software program (PASW, IBM Corp., New York, NY, USA). A $\mathrm{P}$ value of $<0.05$ was considered to be statistically significant.

\section{Results}

\section{Demographic and baseline characteristics}

The mean age of patients was $54.45 \pm 12.04$ years in the ACDF group and $60.10 \pm 10.72$ years in the laminoplasty group. There were no statistically significant differences in age $(\mathrm{P}=0.118)$ and sex ratios between the groups $(\mathrm{P}=0.426)$. Furthermore, the preoperative radiological parameters including CL, SegL, ROM, SegROM, C2-7 SVA, spinal cord SI change on MRI, and K-line were not significantly different between the groups (Table 1). The pre-SegL, which affected the choice of surgical approach, was higher in the laminoplasty group than in the ACDF group, although the difference was not statistically significant. Based on these results, all preoperative radiologic parameters were considered similar between the two groups. The rate of definite spinal cord SI change on MRI was relatively higher in the laminoplasty group than in the ACDF group, but the difference was not statistically significant $(\mathrm{P}=0.167)$.

Preoperative clinical values, except for the VAS-neck score, were not significantly different between the groups. The preoperative VAS-neck score was higher in the laminoplasty group than in the ACDF group (4.36 vs. $1.63, \mathrm{P}=0.010$ ). 
Table 1 Summary of clinical and radiological backgrounds of patients in the ACDF and laminoplasty groups

\begin{tabular}{|c|c|c|c|}
\hline Variables & ACDF group & Laminoplasty group & $P$ value \\
\hline Age (years, mean $\pm \mathrm{SD}$ ) & $54.45 \pm 12.04$ & $60.10 \pm 10.72$ & 0.118 \\
\hline $\operatorname{Sex}(M: F)$ & $17: 5$ & $14: 6$ & $0.426^{\dagger}$ \\
\hline Pre-cervical lordosis $\left({ }^{\circ}\right.$, mean $\left.\pm \mathrm{SD}\right)$ & $8.36 \pm 14.01$ & $8.26 \pm 10.32$ & 0.979 \\
\hline Pre-cervical ROM $\left({ }^{\circ}\right.$, mean $\left.\pm \mathrm{SD}\right)$ & $41.71 \pm 19.25$ & $39.80 \pm 12.51$ & 0.708 \\
\hline Pre-segmental ROM $\left({ }^{\circ}\right.$, mean $\left.\pm \mathrm{SD}\right)$ & $25.48 \pm 15.31$ & $27.75 \pm 8.80$ & 0.556 \\
\hline Pre-C2-7 SVA (mm, mean \pm SD) & $21.67 \pm 11.21$ & $19.53 \pm 10.01$ & 0.569 \\
\hline Spinal cord SI change on MRI (none:intermediate:definite) & $9: 7: 6$ & $3: 8: 9$ & $0.167^{\dagger}$ \\
\hline Pre-VAS-left arm score (mean \pm SD) & $2.50 \pm 1.51$ & $4.46 \pm 2.79$ & 0.104 \\
\hline Pre-VAS-right arm (mean \pm SD) & $2.75 \pm 2.25$ & $3.70 \pm 2.26$ & 0.388 \\
\hline Pre-NDI (mean \pm SD) & $20.13 \pm 15.04$ & $29.90 \pm 15.43$ & 0.196 \\
\hline Pre-PCS (mean \pm SD) & $53.01 \pm 8.76$ & $59.03 \pm 9.06$ & 0.176 \\
\hline Pre-MCS (mean \pm SD) & $48.88 \pm 9.29$ & $46.90 \pm 10.71$ & 0.686 \\
\hline Pre-JOA score (mean \pm SD) & $17.60 \pm 1.64$ & $17.88 \pm 1.58$ & 0.723 \\
\hline
\end{tabular}

The independent $t$-test was performed for variables and presented as mean $\pm \mathrm{SD}{ }^{\dagger}{ }^{\dagger}$, The chi-square test was performed. ACDF, anterior cervical discectomy and fusion; SD, standard deviation; M, male; F, female; Pre, preoperative; MRI, magnetic resonance imaging; SVA, sagittal vertical axis; VAS, visual analog scale; PCS, physical component score; MCS, mental component score; JOA, Japanese Orthopaedic Association; NDI, neck disability index.

\section{Comparison of radiological outcomes}

Postoperative C2-7 CL was higher in the ACDF group than in the laminoplasty group $\left(10.01^{\circ}\right.$ vs. $\left.7.39^{\circ}, \mathrm{P}=0.475\right)$, and the gap of $\mathrm{SegL}$ was decreased in both groups $\left(6.70^{\circ}\right.$ vs. $\left.6.90^{\circ}, \mathrm{P}=0.943\right)$. The rate of reduction in $\mathrm{C} 2-7$ cervical and segmental ROMs was notably higher in the ACDF group than in the laminoplasty group $(41.26 \%$ vs. $16.39 \%$, $\mathrm{P}=0.02 ; 62.88 \%$ vs. $12.57 \%, \mathrm{P}=0.003$, respectively). The postoperative $\mathrm{C} 2-7$ SVA was higher in the ACDF group than in the laminoplasty group; this gap was increased compared to the preoperative value, but it was not statistically significant (23.02 vs. 17.44, $\mathrm{P}=0.070)$. In the ACDF group, the magnitude of lordosis increased in both the $\mathrm{C} 2-7$ cervical and segmental ROMs $\left(1.65^{\circ}\right.$ and $4.48^{\circ}$, respectively). However, there was little change in these parameters in the laminoplasty group (Table 2).

\section{Comparison of clinical outcomes and the $R R$}

There were no statistically significant differences between the groups in the postoperative VAS score, NDI, PCS, MCS, or JOA score. The VAS-neck score, which exhibited a significant difference preoperatively, was similar postoperatively between the groups (2.90 vs. 2.10, $\mathrm{P}=0.321$ ).

The RR was higher in the laminoplasty group than in the ACDF group (57.40\% vs. $42.85 \%, \mathrm{P}=0.449$ ) (Table 2). It is important to highlight that although the RR difference between the groups was not statistically significant, it was greater than $14 \%$. We investigated the factor that mostly affected the difference in RR between the groups. First, RR was $65.00 \%$ with a negative K-line and $44.70 \%$ with a positive $\mathrm{K}$-line, but this was not statistically significant $(\mathrm{P}=0.308)$ (Table 3). Second, the degree of spinal cord SI change on MRI showed a marked difference in terms of 
Table 2 Summary of clinical and radiological outcomes in the ACDF and laminoplasty groups

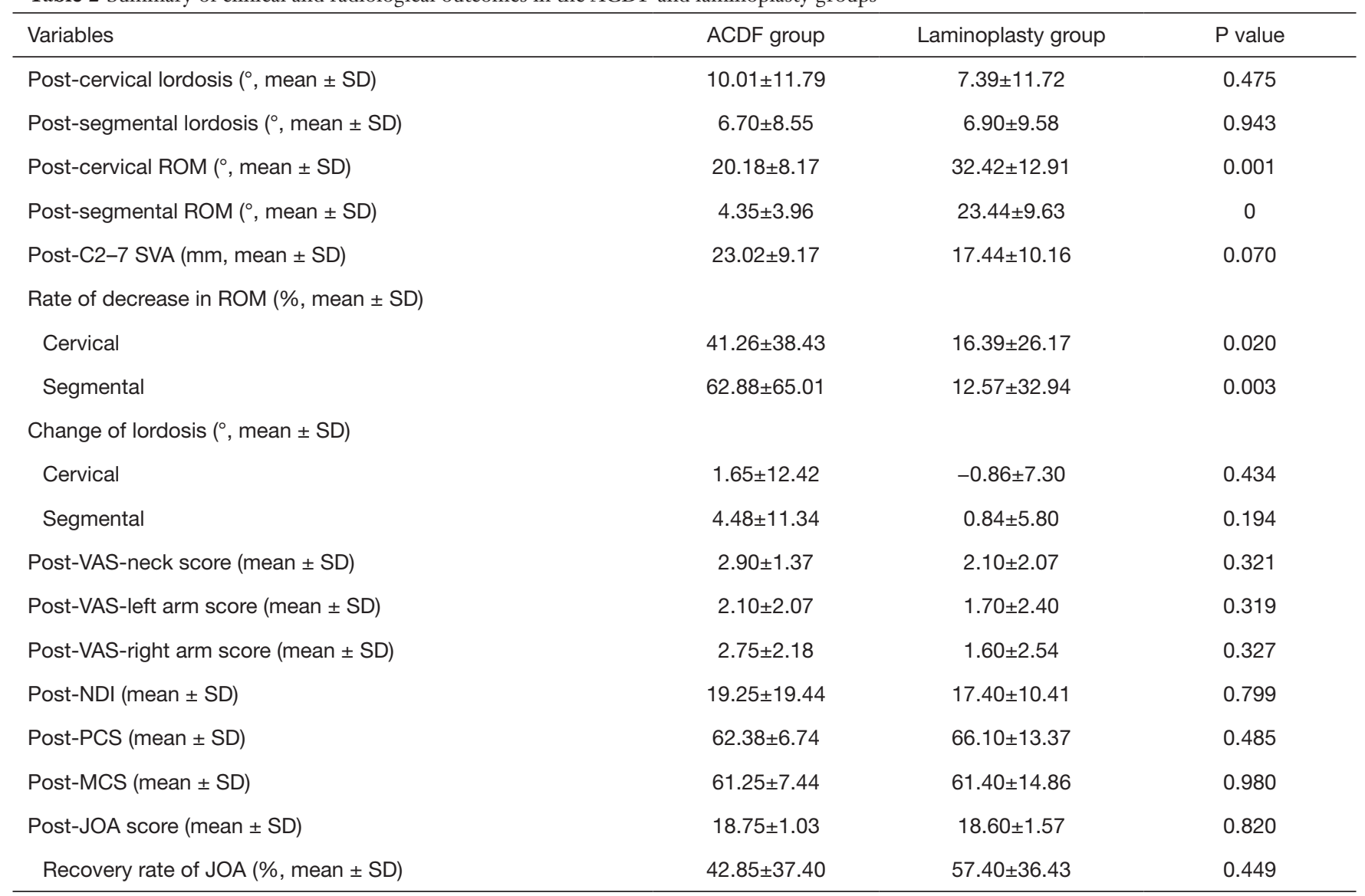

The independent $t$-test was performed for variables and presented as mean \pm SD. ACDF, anterior cervical discectomy and fusion; SD, standard deviation; ROM, range of motion; Post, postoperative; SVA, sagittal vertical axis; VAS, visual analog scale; PCS, physical component score; MCS, mental component score; JOA, Japanese Orthopaedic Association; NDI, neck disability index.

Table 3 Effect of the K-line status on the recovery rate

\begin{tabular}{lcc}
\hline K-line status & Recovery rate $(\%$, mean $\pm \mathrm{SD})$ & P value \\
\hline K-line $(-)$ & $65.00 \pm 33.54$ & 0.308 \\
K-line $(+)$ & $44.70 \pm 37.31$ & \\
\hline
\end{tabular}

The independent $t$-test was performed. SD, standard deviation.

RR, with the total RRs being $97.70 \%$, 55\%, and $52.20 \%$ in the no change, intermediate change, and definite change groups, respectively $(\mathrm{P}=0.002)$. In the ACDF group, these values were $87.50 \%, 37.50 \%$, and $16.67 \%$, respectively $(\mathrm{P}=0.075)$. In the laminoplasty group, the $\mathrm{RR}$ without spinal cord SI change was $100 \%$, signifying a complete recovery from the symptoms, $66.70 \%$ in the intermediate group, and $27.78 \%$ in the definite group $(\mathrm{P}=0.069)$ (Table 4).
Comprehensively, the degree of spinal cord SI change and RR expressed a strikingly negative relationship (Figure 1).

The correlation analysis between changes in radiological parameters and changes in clinical/functional outcome scores (including RR) was performed to identify the relevant correlations. However, no statistically significant correlations were observed (Table 5). Finally, multivariate regression analysis was conducted to further clarify the effect of the various parameters on the RR. The change of SVA, rate of decrease in $\mathrm{ROM}$, change of lordosis, $\mathrm{K}$-line, and operative procedure did not correlate with the RR. Only the spinal cord SI change on MRI tended to reduce the $\mathrm{RR}(\mathrm{P}=0.003)$ (Table 6).

\section{Comparison of surgical outcomes}

Of the 22 cases in the ACDF group, surgery-related 
Table 4 Effects of spinal cord signal intensity changes on MRI on the recovery rates

\begin{tabular}{lccc}
\hline \multirow{2}{*}{ Variables } & \multicolumn{2}{c}{ Spinal cord signal intensity change on MRI } & \multicolumn{2}{c}{ P value } \\
\cline { 2 - 3 } & No change & Indeterminate change & Definite change \\
\hline Total recovery rate $(\%$, mean \pm SD) & $97.70 \pm 12.50$ & $55.00 \pm 29.81$ & $52.20 \pm 25.09$ \\
ACDF recovery rate $(\%$, mean \pm SD) & $87.50 \pm 17.67$ & $37.50 \pm 17.67$ & $16.67 \pm 28.87$ \\
Laminoplasty recovery rate $(\%$, mean \pm SD) & $100.00 \pm 0$ & $66.70 \pm 33.33$ & $27.78 \pm 25.45$ \\
\hline
\end{tabular}

The analysis of variance test was performed. MRI, magnetic resonance imaging; SD, standard deviation; ACDF, anterior cervical discectomy and fusion.

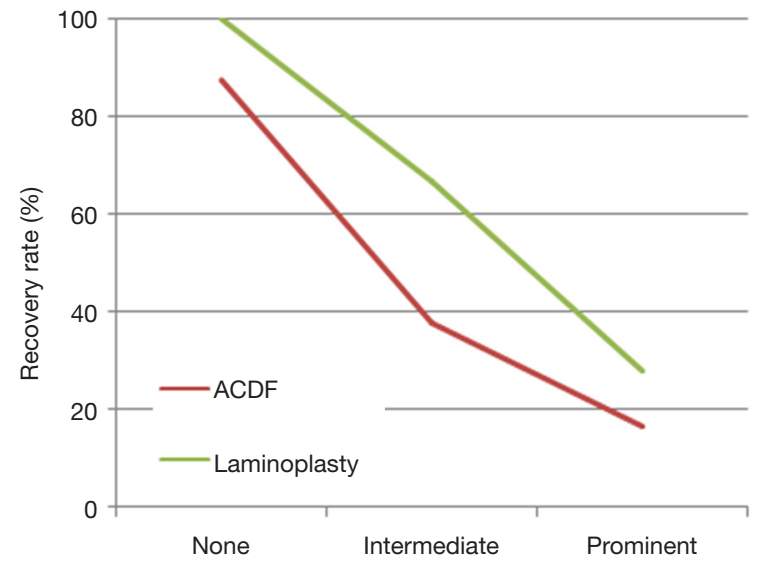

Figure 1 The degree of spinal cord signal intensity (SI) change on magnetic resonance imaging (MRI) significantly affects the recovery rate (RR) in both groups. The greater the spinal cord SI change, the more prominent the tendency for the recovery rate to decrease. ACDF, anterior cervical discectomy and fusion.

Table 5 Effects of changes in cervical alignments on the recovery rate

\begin{tabular}{|c|c|c|c|c|c|}
\hline Variables & $\triangle$ VASn (r/P value) & $\Delta \mathrm{NDI}(\mathrm{r} / \mathrm{P}$ value $)$ & $\triangle \mathrm{PCS}(\mathrm{r} / \mathrm{P}$ value $)$ & $\triangle \mathrm{MCS}(\mathrm{r} / \mathrm{P}$ value) & Recovery rate ( $r / P$ value) \\
\hline \multicolumn{6}{|c|}{ Decrease rate of ROM (\%) } \\
\hline Cervical & $0.180 / 0.475$ & $0.292 / 0.240$ & $-0.158 / 0.533$ & $-0.183 / 0.467$ & $-0.186 / 0.490$ \\
\hline Segmental & $-0.134 / 0.596$ & $0.145 / 0.567$ & $0.025 / 0.920$ & $-0.273 / 0.273$ & $-0.043 / 0.875$ \\
\hline Cervical & $0.293 / 0.238$ & $0.086 / 0.734$ & $0.065 / 0.797$ & $0.038 / 0.882$ & $-0.460 / 0.073$ \\
\hline Segmental & $0.168 / 0.505$ & $-0.054 / 0.830$ & $0.019 / 0.939$ & $0.130 / 0.608$ & $-0.435 / 0.092$ \\
\hline
\end{tabular}

Correlation analysis was performed to analyze the correlation between parameters and clinical outcomes. $r$, Pearson correlation coefficient; VASn, visual analog scale neck; PCS, physical component score; MCS, mental component score; NDI, neck disability index; SVA, sagittal vertical axis. 
Table 6 Multiple regression analysis of factors affecting the recovery rate

\begin{tabular}{|c|c|c|c|c|}
\hline Variables & \multicolumn{2}{|c|}{ Unstandardized coefficient } & $\begin{array}{l}\text { Standardized coefficient } \\
\text { (beta) }\end{array}$ & $P$ value \\
\hline Change of SVA (mm) & 0.383 & 0.814 & 0.097 & 0.652 \\
\hline \multicolumn{5}{|l|}{ Decrease rate of ROM (\%) } \\
\hline Cervical & -0.379 & 0.413 & -0.507 & 0.144 \\
\hline \multicolumn{5}{|l|}{ Change of lordosis $\left(^{\circ}\right)$} \\
\hline Cervical & 0.947 & 1.669 & 0.238 & 0.588 \\
\hline Segmental & -1.854 & 1.590 & -0.428 & 0.282 \\
\hline Spinal cord SI change on MRI & -34.742 & 7.842 & -0.770 & 0.003 \\
\hline
\end{tabular}

Multivariate regression test was performed. SE, stand error of the mean; SVA, sagittal vertical axis; ROM, range of motion; SI, signal intensity; MRI, magnetic resonance imaging; OP, operative.
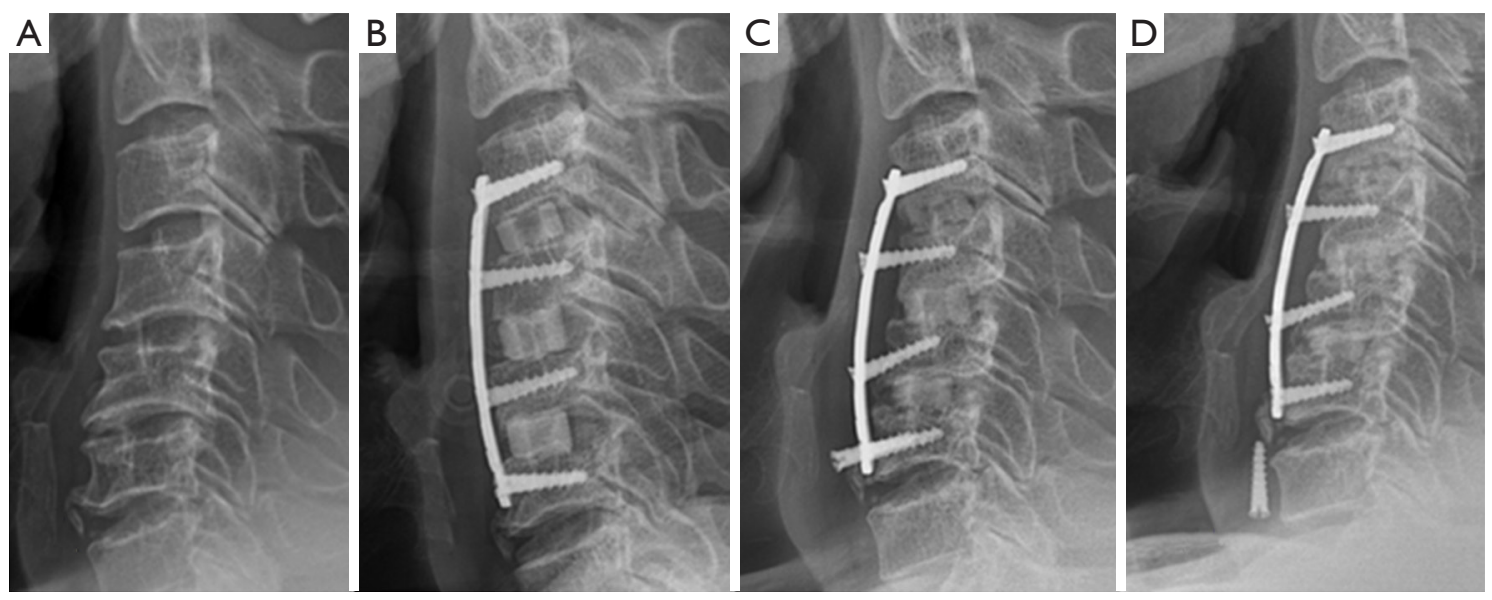

Figure 2 A case of complication in the anterior cervical discectomy and fusion (ACDF) group. In a 55-year-old male patient, severe spondylosis with sagittal imbalance at the C3-4-5-6 levels was observed. (A) ACDF of the C3-4-5-6 levels was performed, and the radiography immediately postoperatively is shown. (B) One of the C6 screws shows antero-pulsion, and segmental kyphosis was aggravated at 6 months postoperatively. A screw was completely out of the vertebral body at 12 months postoperatively (C), and kyphotic change was maintained (D).

complications occurred during the entire follow-up period in 8 cases. There were 2 cases of screw loosening, 4 cases of screw breakage ( 3 cases at 6 months and 1 case at 12 months postoperatively), 1 case of screw antero-pulsion at 12 months postoperatively, and 1 case of bone graft material displacement (Figure 2A,B,C,D). In the cases of screw antero-pulsion and graft displacement, the patients underwent reoperation. There were no cases of hematoma and/or airway obstruction. Therefore, the incidence rate of complications in the ACDF group was $36.3 \%$ and the revision rate was $9.1 \%$. In the laminoplasty group, there were no cases of surgery-related complications, including postoperative C5 palsy and/or device failure, during the entire follow-up period (Table 7).

According to the CT scans, the total final fusion rate in the ACDF group was $62.12 \%$. There were 3 cases in which 
Table 7 Surgical complications and fusion rate in the ACDF group

\begin{tabular}{|c|c|}
\hline Complications and fusion rate & Number of cases \\
\hline \multicolumn{2}{|l|}{ Complication } \\
\hline ACDF & 8 \\
\hline Screw loosening & 2 \\
\hline Screw breakage at 6 months & 3 \\
\hline Screw breakage at 12 months & 1 \\
\hline Screw expulsion at 12 months & $1^{\dagger}$ \\
\hline Bone graft displacement & $1^{\dagger}$ \\
\hline Hematoma & 0 \\
\hline Total incidence rate (\%) & 36.3 \\
\hline Revision rate (\%) & 9.1 \\
\hline \multicolumn{2}{|l|}{ Laminoplasty } \\
\hline C5 palsy & 0 \\
\hline Device displacement & 0 \\
\hline \multicolumn{2}{|l|}{ Fusion status (ACDF group only) $(n=22)$} \\
\hline \multicolumn{2}{|l|}{ Fused: not fused (segments) } \\
\hline 3:00 & 4 \\
\hline 2:01 & 11 \\
\hline $1: 02$ & 7 \\
\hline 0:03 & 0 \\
\hline Total number of fused segments & 41 \\
\hline Total number of unfused segments* & 25 \\
\hline Fusion rate (\%) & 62.12 \\
\hline Number of cases of subsidence & 3 (5 levels) \\
\hline Subsidence rate (\%) & 7.57 \\
\hline
\end{tabular}

${ }^{\dagger}$, reoperation was performed. *, in all unfused segments and segments with subsidence, allograft bone block was used as graft material. ACDF, anterior cervical discectomy and fusion.

complete bone fusion was observed at all 3 levels, 11 cases showed 2 levels of fusion and 1 level of nonunion, 7 cases showed 1 level of fusion and 2 levels of nonunion, and no cases showed 3 levels of nonunion. Therefore, the total numbers of fused and nonunion segments were 41 and 25 , respectively. Moreover, there were 5 levels of subsidence in 3 cases, and the subsidence rate was $7.57 \%$ (Table 7).

\section{Comparison of serial changes of radiologic parameters}

In the ACDF group, the SegL increased considerably from $2.21^{\circ}$ to $8.37^{\circ}$ at 6 months postoperatively $(\mathrm{P}=0.026)$; however, this decreased substantially to $6.50^{\circ}$ at 12 months postoperatively $(\mathrm{P}=0.003)$. $\mathrm{C} 2-7 \mathrm{CL}$ in the ACDF group showed similar changes. Preoperative $\mathrm{CL}$ was $8.36^{\circ}$, which increased markedly to $12.00^{\circ}$ at 6 months postoperatively, and subsequently decreased to $9.77^{\circ}$ at 12 months postoperatively $(\mathrm{P}=0.037)$ (Figure $3 A, B)$. Conversely, in the laminoplasty group, postoperative radiological parameters did not change notably compared with the preoperative values (Figure 3C,D). C2-7 cervical ROM was considerably reduced at 6 months postoperatively in both groups, and this was more prominent in the ACDF group ( $41.7^{\circ}$ to $22.2^{\circ}, \mathrm{P}<0.001$ vs. $39.8^{\circ}$ to $\left.31.0^{\circ}, \mathrm{P}=0.001\right)$. Thereafter, these values did not show any significant changes in either group. Also, the serial change of C2-7 SVA did not show any notable changes before or after surgery in either group (Figure $4 A, B, C, D$ ).

\section{Discussion}

In this study, we analyzed various parameters that could affect clinical and radiological outcomes after surgical treatment in patients with CSM. There were no significant preoperative differences in demographic, radiological, and clinical backgrounds between the groups. Generally, in the determination of the surgical method, the magnitude of kyphosis of the main cervical lesion was considered. An anterior approach was performed if severe kyphotic alignment was present; otherwise, a posterior approach was considered. However, there were no significant differences in the preoperative magnitude of kyphosis between the two groups. The most important difference between the two surgical methods is the joint fixation. The ACDF procedure must inevitably unite the three levels of joints, whereas laminoplasty can preserve the joint of the index cervical levels. The variations in these surgical procedures resulted in pronounced differences in ROM postoperatively. However, since the functional outcomes, including VAS score, NDI, and PCS/MCS, were improved in both groups postoperatively, a reduced ROM does not appear to have a prominent effect on clinical outcome.

Liu et al. reported that both ACDF and laminoplasty are both effective procedures for treating multiple CSM, though ACDF has a higher rate of decrease in ROM and more complications (24). They reported that the incidence of complications in ACDF was 36\%. Luo et al. also published a similar study, although they claimed that a definitive conclusion regarding the most effective surgical 

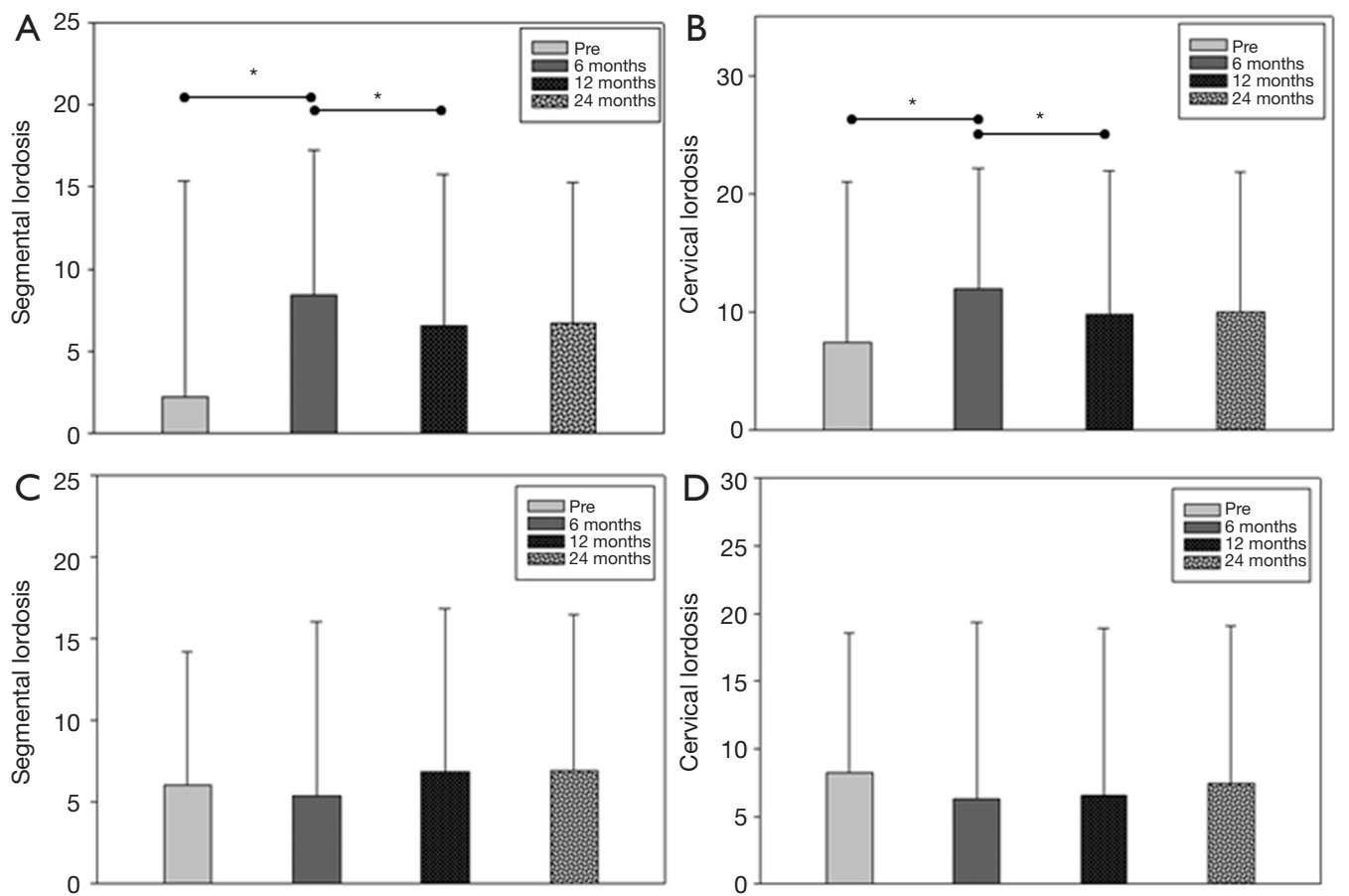

Figure 3 The anterior cervical discectomy and fusion (ACDF) group shows a significant increase in both segmental and cervical lordosis at 6 months postoperatively, followed by a marked decrease at 12 months postoperatively (A,B). The laminoplasty group does not exhibit notable change of lordosis postoperatively $(\mathrm{C}, \mathrm{D})$. $^{*}, \mathrm{P}<0.05$.
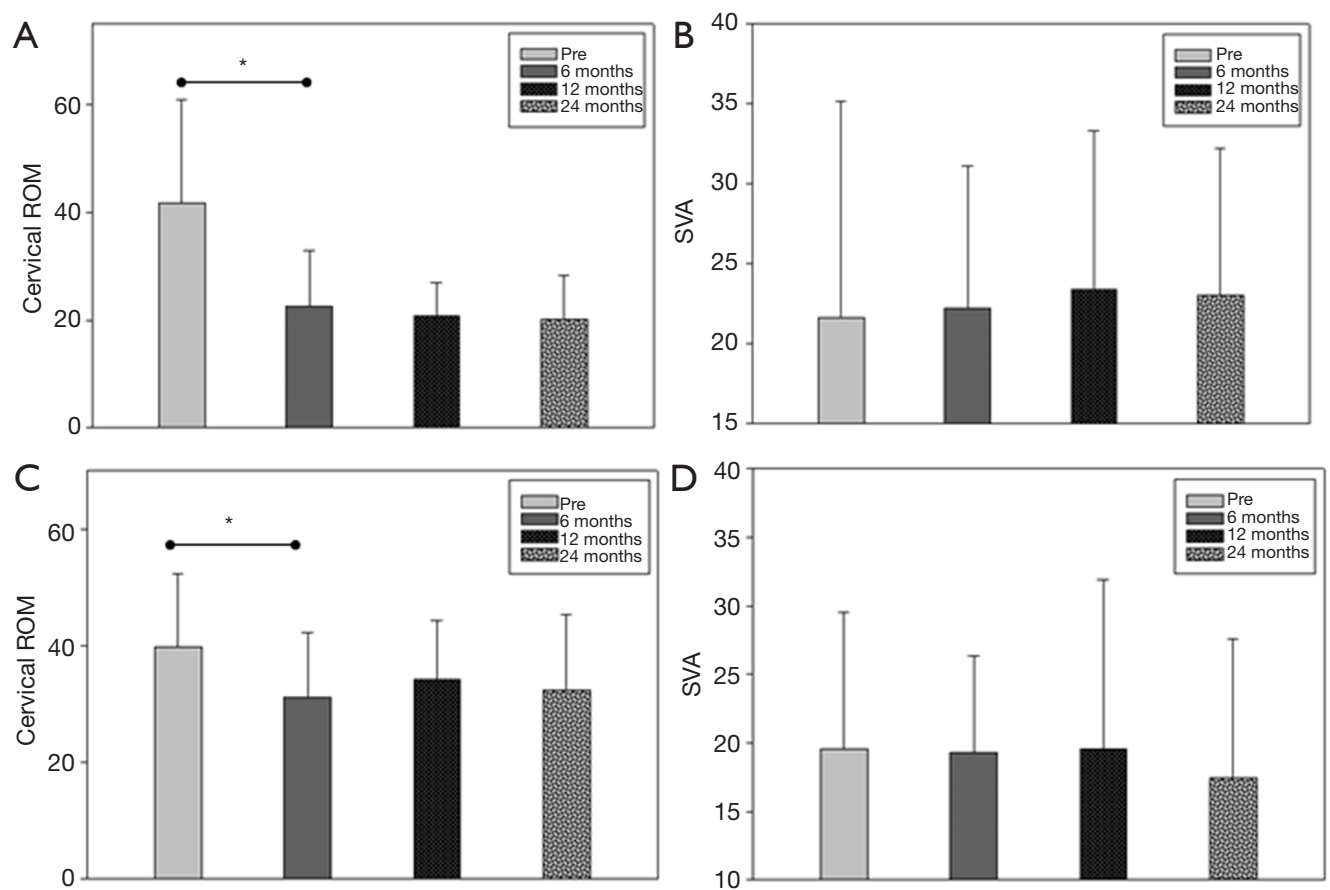

Figure 4 The anterior cervical discectomy and fusion (ACDF) and laminoplasty groups show a considerable decrease in cervical range of motion (ROM) postoperatively, which is maintained until 2 years (A,C). The ACDF and laminoplasty groups do not show any substantial change of $\mathrm{C} 2-7$ sagittal vertical axis (SVA) postoperatively until the 2-year follow-up (B,D). * $\mathrm{P}<0.05$. Pre, preoperatively. 
approach for the treatment of CSM could not be reached, noting that there was no significant difference in the RR between the two methods. Moreover, they reported that higher rates of surgical complication and reoperation were identified in the ACDF group than in the laminoplasty group (15). The results of our present study are analogous to the findings of Luo et al.

Fujiyoshi et al. reported that the negative K-line group can show insufficient neurologic improvement after posterior decompression surgery (20). According to our results, although the RR was slightly higher in the negative $\mathrm{K}$-line group, it was not statistically significant, which suggests that preoperative cervical alignment is not the only factor affecting the surgical outcome.

We performed multivariate regression analysis of various combinations of factors to identify the significant factors affecting the RR. Our analysis revealed that spinal cord SI change on T2-weighted MRI is the one key variable that could significantly affect the RR. In previous studies, Matsuda et al. investigated 29 surgical cases of patients treated for cervical myelopathy, and they reported that increased magnetic resonance SI was associated with a worse clinical condition in patients with CSM (25). Fernández de Rota et al. also reported that multi segmental high-intensity change on T2-weighted imaging (T2WI) is a sensitive indicator of clinical outcomes in patients with advanced myelopathy, and can be used as a predictor of poor functional recovery (26). Yukawa et al. reported that increased SI in T2WI preoperatively was correlated with postoperative JOA score and RR in a study of 104 patients who had cervical expansive laminoplasty with cervical compressive myelopathy (27). Similarly, in our study, changes in the various radiological parameters did not have a direct effect on the RR; spinal cord SI change on MRI was the only independent factor. There were notable differences in postoperative ROM of the cervical spine due to differences in the surgical methods, but there were no substantial postoperative differences between the groups in NDI, MCS, or PCS.

Our study showed that rate of decrease in cervical ROM after laminoplasty was $16.3 \%$, which is similar to the $13 \%$ reported by Machino et al. (28). Cho et al. also reported that $14.7 \%$ of cases showed a considerable decrease of cervical ROM following laminoplasty (29). In the present study, the rate of decrease in cervical ROM after ACDF was $62.8 \%$. Although these (significant) differences between the two groups do not have a remarkable effect on postoperative clinical and functional outcomes, a higher rate of decrease in the $\mathrm{ROM}$ can be a potential risk factor for adjacent segment disease in patients who undergo ACDF. These disadvantages become even more apparent when the postoperative complication rates between the two groups are compared. Our study found a $36.3 \%$ incidence rate of complications and a $9.1 \%$ revision rate in the ACDF group. Veeravagu et al. reported that the revision rate for multilevel ACDF was $10.7 \%$ at the 2 -year follow-up, which is very similar to our result (30). In contrast, no complications associated with laminoplasty occurred in our study. Zhu et al. reviewed surgical outcomes between the anterior and posterior approaches for the treatment of multilevel CSM and reported that there was no apparent difference in the functional RR. They also found that complication and reoperation rates were significantly higher in the anterior approach group than in the posterior approach group (31).

We also investigated the fusion rate in the ACDF group. The overall fusion rate was $62 \%$ at the final follow-up. Emery et al. reported that the pseudoarthrosis rates of single-level fusions are low, but those of three-level cervical procedures are as high as $40 \%$ (32). The fusion rate may be closely related to the presence or absence of anterior plating. Moreover, in the case of long-level surgeries, it is even more critical. In the present study, all cases in the ACDF group were reinforced with anterior plating. Wang et al. insisted that fusion rates were improved with the use of a cervical anterior plate, and reported a pseudoarthrosis rate of $18 \%$ in the three-level ACDF group (33). However, their fusion rates were assessed by flexion-extension radiographs, not CT scans; therefore, their results are likely to be superior to our current fusion rates.

Using CT scans, we found that the subsidence rate was $7.5 \%$. Given that anterior plate fixation was performed in all patients in the ACDF group, our results are considered to be highly reliable. Shi $e t$ al. investigated the subsidence rate after three-level ACDF and compared the rates of the ACDF with anterior plate group and the stand-alone anchored spacer group. Their study showed that the subsidence rates were $0 \%$ and $16.7 \%$ in the ACDF with anterior plate and stand-alone anchored spacer groups, respectively (34). We can also confirm similar findings in a single-level ACDF study. Han et al. reported that the standalone cage cervical fusion group showed a higher subsidence rate than the plate-assisted cervical fusion group (35). However, their investigation only used plain radiographs, rather than CT scans.

The laminoplasty group showed greater preservation of cervical alignment and ROM than the ACDF group, 
and there were no statistically significant differences in the clinical outcomes of the groups. Also, the ACDF group showed higher surgery-related complications compared to the laminoplasty group, and the restoration of CL was not maintained until 12 months postoperatively.

\section{Conclusions}

Multilevel laminoplasty showed better radiological and similar clinical outcomes than three-level ACDF. Moreover, ACDF led to more surgical complications than multilevel laminoplasty. The independent risk factor for poor clinical outcomes was spinal cord SI change on preoperative MRI. Therefore, we recommend multilevel laminoplasty rather than three-level ACDF in the treatment of patients with multilevel CSM.

\section{Acknowledgments}

Funding: This research was supported by a grant of the Korea Health Technology R\&D Project through the Korea Health Industry Development Institute (KHIDI), funded by the Ministry of Health \& Welfare, Republic of Korea (grant number: HI19C1234). This research was also supported by the Bio \& Medical Technology Development Program of the NRF funded by the Korean government, MSIP (NRF2015M3A9C6065075).

\section{Footnote}

Conflicts of Interest: All authors have completed the ICMJE uniform disclosure form (available at http://dx.doi. org/10.21037/qims-20-220). The authors have no conflicts of interest to declare.

Ethical Statement: This study was approved by Yonsei University institutional review board. (IRB No.: 4-20120687). Informed consent was waived due to the retrospective analyses design.

Open Access Statement: This is an Open Access article distributed in accordance with the Creative Commons Attribution-NonCommercial-NoDerivs 4.0 International License (CC BY-NC-ND 4.0), which permits the noncommercial replication and distribution of the article with the strict proviso that no changes or edits are made and the original work is properly cited (including links to both the formal publication through the relevant DOI and the license).
See: https://creativecommons.org/licenses/by-nc-nd/4.0/.

\section{References}

1. Young WF. Cervical spondylotic myelopathy: a common cause of spinal cord dysfunction in older persons. Am Fam Physician 2000;62:1064-70, 1073. Erratum in: Am Fam Physician 2001 May 15;63(10):1916.

2. Zileli M, Borkar SA, Sinha S, Reinas R, Alves ÓL, Kim S-H, Pawar S, Murali B, Parthiban J. Cervical Spondylotic Myelopathy: Natural Course and the Value of Diagnostic Techniques -WFNS Spine Committee Recommendations. Neurospine 2019;16:386-402.

3. Parthiban J, Alves OL, Chandrachari KP, Ramani P, Zileli M. Value of Surgery and Nonsurgical Approaches for Cervical Spondylotic Myelopathy: WFNS Spine Committee Recommendations. Neurospine 2019;16:403-7.

4. Oh JK. Do Not Think to See One Side and Know the Whole - We Have to Understand Cervical Spine Dynamics Not Only Static State. Neurospine 2019;16:454-5.

5. Lebl DR, Hughes A, Cammisa FP Jr, O'Leary PF. Cervical spondylotic myelopathy: pathophysiology, clinical presentation, and treatment. HSS J 2011;7:170-8.

6. Joaquim AF, Baum GR, Tan LA, Riew KD. Dynamic Cord Compression Causing Cervical Myelopathy. Neurospine 2019;16:448-53.

7. Ito T, Oyanagi K, Takahashi H, Takahashi HE, Ikuta F. Cervical spondylotic myelopathy. Clinicopathologic study on the progression pattern and thin myelinated fibers of the lesions of seven patients examined during complete autopsy. Spine (Phila Pa 1976) 1996;21:827-33.

8. Quinn JC, Kiely PD, Lebl DR, Hughes AP. Anterior surgical treatment of cervical spondylotic myelopathy: review article. HSS J 2015;11:15-25.

9. Deora H, Kim SH, Behari S, Rudrappa S, Rajshekhar V, Zileli M, Parthiban JKBC. Anterior Surgical Techniques for Cervical Spondylotic Myelopathy: WFNS Spine Committee Recommendations. Neurospine 2019;16:408-20.

10. Matz PG, Anderson PA, Groff MW, Heary RF, Holly LT, Kaiser MG, Mummaneni PV, Ryken TC, Choudhri TF, Vresilovic EJ, Resnick DK. Cervical laminoplasty for the treatment of cervical degenerative myelopathy. J Neurosurg Spine 2009;11:157-69.

11. Bajamal AH, Kim SH, Arifianto MR, Faris M, Subagio EA, Roitberg B, Udo-Inyang I, Belding J, Zileli M, Parthiban JKBC. Posterior Surgical Techniques for Cervical 
Spondylotic Myelopathy: WFNS Spine Committee

Recommendations. Neurospine 2019;16:421-34.

12. Hirabayashi K, Watanabe K. A Review of My Invention of Expansive Laminoplasty. Neurospine 2019;16:379-82.

13. Fehlings MG, Barry S, Kopjar B, Yoon ST, Arnold P, Massicotte EM, Vaccaro A, Brodke DS, Shaffrey C, Smith JS, Woodard E, Banco RJ, Chapman J, Janssen M, Bono C, Sasso R, Dekutoski M, Gokaslan ZL. Anterior versus posterior surgical approaches to treat cervical spondylotic myelopathy: outcomes of the prospective multicenter AOSpine North America CSM study in 264 patients. Spine (Phila Pa 1976) 2013;38:2247-52.

14. Mummaneni PV, Kaiser MG, Matz PG, Anderson PA, Groff MW, Heary RF, Holly LT, Ryken TC, Choudhri TF, Vresilovic EJ, Resnick DK; Joint Section on Disorders of the Spine and Peripheral Nerves of the American Association of Neurological Surgeons and Congress of Neurological Surgeons. Cervical surgical techniques for the treatment of cervical spondylotic myelopathy. J Neurosurg Spine 2009;11:130-41.

15. Luo J, Cao K, Huang S, Li L, Yu T, Cao C, Zhong R, Gong M, Zhou Z, Zou X. Comparison of anterior approach versus posterior approach for the treatment of multilevel cervical spondylotic myelopathy. Eur Spine J 2015;24:1621-30.

16. Kim DH, Lee CH, Ko YS, Yang SH, Kim CH, Park SB, Chung CK. The Clinical Implications and Complications of Anterior Versus Posterior Surgery for Multilevel Cervical Ossification of the Posterior Longitudinal Ligament; An Updated Systematic Review and MetaAnalysis. Neurospine 2019;16:530-41.

17. Moghaddamjou A, Fehlings MG. An Age-old Debate: Anterior Versus Posterior Surgery for Ossification of the Posterior Longitudinal Ligament. Neurospine 2019;16:544-7.

18. Dru AB, Lockney DT, Vaziri S, Decker M, Polifka AJ, Fox WC, Hoh DJ. Cervical Spine Deformity Correction Techniques. Neurospine 2019;16:470-82.

19. Iwasaki M, Okuda S, Miyauchi A, Sakaura H, Mukai Y, Yonenobu K, Yoshikawa H. Surgical strategy for cervical myelopathy due to ossification of the posterior longitudinal ligament: Part 2: Advantages of anterior decompression and fusion over laminoplasty. Spine (Phila $\mathrm{Pa} 1976$ ) 2007;32:654-60.

20. Fujiyoshi T, Yamazaki M, Kawabe J, Endo T, Furuya T, Koda M, Okawa A, Takahashi K, Konishi H. A new concept for making decisions regarding the surgical approach for cervical ossification of the posterior longitudinal ligament: the K-line. Spine (Phila Pa 1976) 2008;33:E990-3 .

21. Taniyama T, Hirai T, Yoshii T, Yamada T, Yasuda H, Saito M, Inose H, Kato T, Kawabata S, Okawa A. Modified $\mathrm{K}$-line in magnetic resonance imaging predicts clinical outcome in patients with nonlordotic alignment after laminoplasty for cervical spondylotic myelopathy. Spine (Phila Pa 1976) 2014;39:E1261-8.

22. Kast E, Derakhshani S, Bothmann M, Oberle J. Subsidence after anterior cervical inter-body fusion. A randomized prospective clinical trial. Neurosurg Rev 2009;32:207-14.

23. Hirabayashi K, Miyakawa J, Satomi K, Maruyama T, Wakano K. Operative results and postoperative progression of ossification among patients with ossification of cervical posterior longitudinal ligament. Spine (Phila $\mathrm{Pa}$ 1976) 1981;6:354-64.

24. Liu T, Yang HL, Xu YZ, Qi RF, Guan HQ. ACDF with the PCB cage-plate system versus laminoplasty for multilevel cervical spondylotic myelopathy. J Spinal Disord Tech 2011;24:213-20.

25. Matsuda Y, Miyazaki K, Tada K, Yasuda A, Nakayama T, Murakami H, Matsuo M. Increased MR signal intensity due to cervical myelopathy. Analysis of 29 surgical cases. J Neurosurg 1991;74:887-92.

26. Fernández de Rota JJ, Meschian S, Fernández de Rota A, Urbano V, Baron M. Cervical spondylotic myelopathy due to chronic compression: the role of signal intensity changes in magnetic resonance images. J Neurosurg Spine 2007;6:17-22.

27. Yukawa Y, Kato F, Yoshihara H, Yanase M, Ito K. MR T2 image classification in cervical compression myelopathy: predictor of surgical outcomes. Spine (Phila Pa 1976) 2007;32:1675-8; discussion 1679.

28. Machino M, Yukawa Y, Hida T, Ito K, Nakashima H, Kanbara S, Morita D, Kato F. Cervical alignment and range of motion after laminoplasty: radiographical data from more than 500 cases with cervical spondylotic myelopathy and a review of the literature. Spine (Phila $\mathrm{Pa}$ 1976) 2012;37:E1243-50.

29. Cho Y. The Change of Range of Motion at Anterior Compression of the Cervical Cord after Laminoplasty in Patients with Cervical Spondylotic Myelopathy. Korean J Spine 2016;13:177-82.

30. Veeravagu A, Cole T, Jiang B, Ratliff JK. Revision rates and complication incidence in single- and multilevel anterior cervical discectomy and fusion procedures: an administrative database study. Spine J 2014;14:1125-31.

31. Zhu B, Xu Y, Liu X, Liu Z, Dang G. Anterior approach 
versus posterior approach for the treatment of multilevel cervical spondylotic myelopathy: a systemic review and meta-analysis. Eur Spine J 2013;22:1583-93.

32. Emery S, Fisher J, Bohlman H. editors. Higher incidence of pseudarthrosis and poor outcomes for three-level anterior cervical discectomy and fusion. Presented at the Annual Meeting of the Cervical Spine Research Society, Palm Beach, FL, 1996.

33. Wang JC, McDonough PW, Kanim LE, Endow KK, Delamarter RB. Increased fusion rates with cervical plating for three-level anterior cervical discectomy and fusion. Spine (Phila Pa 1976) 2001;26:643-6.

34. Shi S, Liu ZD, Li XF, Qian L, Zhong GB, Chen FJ. Comparison of plate-cage construct and stand-alone anchored spacer in the surgical treatment of three-level cervical spondylotic myelopathy: a preliminary clinical study. Spine J 2015;15:1973-80.

35. Han SY, Kim HW, Lee CY, Kim HR, Park DH. StandAlone Cages for Anterior Cervical Fusion: Are There No Problems? Korean J Spine 2016;13:13-9.
Cite this article as: Lee JJ, Lee N, Oh SH, Shin DA, Yi S, Kim KN, Yoon DH, Shin HC, Ha Y. Clinical and radiological outcomes of multilevel cervical laminoplasty versus threelevel anterior cervical discectomy and fusion in patients with cervical spondylotic myelopathy. Quant Imaging Med Surg 2020;10(11):2112-2124. doi: 10.21037/qims-20-220 